(๑) И.И. АВЕРИНА, М.Ю. МИРОНЕНКО, О.Н. КИСЛИЦИНА, О.Л. БОКЕРИЯ, 2015

๑ АННАЛЫ АРИТМОЛОГИИ, 2015

удк 616.12-007.1-089.168-06:616.12-008.318-073.432.19

DOI: 10.15275/annaritmol.2015.3.4

ПРЕДИКТОРЫ ВОЗНИКНОВЕНИЯ НАРУШЕНИЙ РИТМА СЕРДЦА В ПОСЛЕОПЕРАЦИОННОМ ПЕРИОДЕ ПО ДАННЫМ ТКАНЕВОЙ ДОППЛЕР-ЭХОКАРДИОГРАФИИ И МЕТОДА ОТСЛЕЖИВАНИЯ ЧАСТИЦ (SPECKLE TRACKING) У БОЛЬНЫХ С ПРИОБРЕТЕННЫМИ ПОРОКАМИ СЕРДЦА

Тип статьи: оригинальная статья

И.И. Аверина, М.Ю. Мироненко, О.Н. Кислищина, О.Л. Бокерия 
ФГБУ «Научный центр сердечно-сосудистой хирургии им. А.Н. Бакулева» Минздрава России (директор академик РАН и РАМН Л.А. Бокерия); Рублевское шоссе, 135, Москва, 121552, Российская Федерация

Аверина Ирина Ивановна, канд. мед. наук, ст. науч. сотр.; e-mail: averina_ii@mail.ru;

Мироненко Марина Юрьевна, канд. мед. наук, врач ультразвуковой диагностики;

Кислицына Ольга Николаевна, канд. мед. наук, ст. науч. сотр.;

Бокерия Ольга Леонидовна, доктор мед. наук, профессор, гл. науч. сотр., зам. заведующего отделением

\begin{abstract}
Цель. Выявить предикторы возникновения нарушений ритма сердиа после хирургической коррекции по данным эхокардиографии, тканевой допплер-эхокардиографии, метода отслеживания частии, магнитно-резонансной томографии (МРТ) сердиа с контрастированием у больных с аортальными и митральными пороками.

Материал и методы. Обследовано 144 пациента с аортальными и митральными пороками: 99 мужчин и 45 женщин в возрасте от 18 до 72 лет (средний возраст 46, 7士15,1 года). Пациенты обследовались исходно до операции, в раннем послеоперационном периоде (8-14 дней) и через 12-36 мес после хирургической коррекции порока. Всем больным проводилось общеклиническое обследование, рентгенография, электрокардиография, эхокардиография, включая тканевую допплер-эхокардиографию, метод отслеживания частиц. Исходно и после операции проводилась МРТ сердиа с контрастным усилением. В зависимости от наличия осложнений пациенты были разделены на группы, отражающие прогноз: группа 0 - больные без нарушений ритма сердиа; группа 1 - пациенты, у которых в послеоперационном периоде были нарушения ритма сердиа (фибрилляция предсердий, желудочковая тахикардия, блокада ножек пучка Гиса).

Результаты. Прогностической значимостью для нарушений ритма сердиа (фибрилляции предсердий, трепетания предсердий) в послеоперационном периоде обладают увеличенные объем и размер левого желудочка (ЛЖ) и левого предсердия, повышенный индекс относительной толщины стенки по данным МРТ, миокардиальный стресс ЛЖ, сниженный интегральный систолический индекс ремоделирования, сниженная функция митрального кольца, деформация левого и правого предсердий, снижение скорости ротации верхушки ЛЖ. В результате многофакторного анализа, построения регрессионной модели Кокса выявлена максимально качественная модель прогноза нарушений ритма сердиа, которая состоит из индекса относительной толщины стенки на уровне папиллярных мыши, определенного по данным МРT, фракции укорочения, соотношения скоростей раннего и позднего диастолического потока (E/A) ЛЖ, продольного смещения латеральной части фиброзного кольца трикуспидального клапана по данным тканевой допплер-эхокардиографии. Максимальное влияние на прогноз было выявлено для индекса относительной толщины стенки на уровне папиллярных мыши, по данным МРТ сердиа с контрастированием, отношения Е/А ЛЖ, скручивания верхушки ЛЖ.

Заключение. Показатели, обладающие прогностической ценностью для нарушений ритма сердиа в послеоперационном периоде, отражсют универсальный процесс ремоделирования с развитием диастолической и систолической дисфункций, повреждение продольной и ииркулярной функций ЛЖ, продольной функции левого предсердия и функции митрального клапана.
\end{abstract}

Ключевые слова: векторный анализ 2D-изображения; метод отслеживания частии speckle tracking; фибрилляция предсердий, прогноз.

\title{
PREDICTORS OF CARDIAC ARRHYTHMIAS IN THE POSTOPERATIVE PERIOD BY ECHOCARDIOGRAPHY, TISSUE DOPPLER AND SPECKLE TRACKING IN PATIENTS WITH CONGENITAL HEART DISEASES
}

\section{I.I. Averina, M.Yu. Mironenko, O.N. Kislitsina, O.L. Bockeria}

A.N. Bakoulev Scientific Center for Cardiovascular Surgery; Rublevskoe shosse, 135, Moscow, 121552, Russian Federation

Averina Irina Ivanovna, MD, PhD, Senior Research Associate; e-mail: averina_ii@mail.ru; Mironenko Maria Yur'evna, MD, PhD, Ultrasonic Diagnostics Physician;

Kislitsina Ol'ga Nikolaevna, MD, PhD, Senior Research Associate;

Bockeria Olga Leonidovna, MD, PhD, DSc, Professor, Chief Research Associate, Deputy Chief of Department

Objective. To identify predictors of cardiac arrhythmias after surgical treatment by echocardiography, tissue Doppler and speckle tracking, magnetic resonance imaging (MRI) in patients with aortic and mitral valve diseases.

Material and methods. The study involved 144 patients with aortic and mitral valve diseases: 99 men and 45

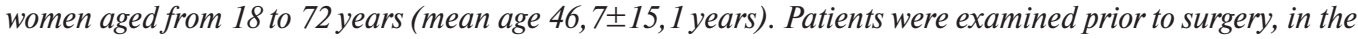
early postoperative period (8-14 days) and 12-36 months after the surgery. All patients underwent clinical examination, radiography, electrocardiography, speckle tracking, MRI of the heart. Depending on the presence of complications, patients were divided into groups, reflecting the outcomes: group 0 - patients with 
a favorable prognosis; group 1 - patients who had postoperative atrial fibrillation, ventricular tachycardia, bundle-branch block.

Results. Prognostic value for cardiac arrhythmias (atrial fibrillation, atrial flutter) in the postoperative period have increased volume and size of left ventricular $(L V)$ and left atrium, increased wall thickness index by MRI, left ventricular myocardial stress, reduced systolic integral index of remodeling, reduced mitral ring function, deformation of left and right atria, reduced speed of the LV apex rotation. In multivariate analysis the most qualitative model of the arrhythmia outcomes was identified, which consists of the wall thickness index at the level of papillary muscles (PM) defined by MRI, fractional shortening, the relationship of early and late diastolic mitral flow (E/A), longitudinal displacement of the lateral part of the tricuspid valve fibrous ring. Maximum coefficient $\beta$, and therefore the greatest impact on prognosis has been identified for the wall thickness index at the level of PM on MRI, the relationship E/A LV, LV torsion.

Conclusion. The indicators with predictive value for the arrhythmia in the postoperative period reflect the universal process of remodeling with the development of diastolic and systolic dysfunction, damage of longitudinal and circular functions of $L V$, longitudinal function of left atrium and the mitral valve function.

Key words: vector velocity imaging; speckle tracking; atrial fibrillation, prognosis.

\section{Введение}

Э хокардиографические данные и новые методы визуализации миокарда - векторный анализ 2D-изображения, метод отслеживания частиц speckle tracking - позволили количественно оценивать механику движения сердца, функцию желудочков и предсердий, проводить раннюю диагностику и контроль лечения сердечной недостаточности, прогнозировать возникновение нарушений ритма сердца.

По современным представлениям, приобретенный порок сердца изначально вызывает субклиническую дисфункцию миокарда, затем происходит ремоделирование сердца и в последующем появляются симптомы сердечной недостаточности, нарушения ритма. Традиционно отбор пациентов на оперативное лечение базируется на наличии симптомов, в том числе и нарушений ритма сердца (НРС), изменении размера и объема левого желудочка (ЛЖ), фракции выброса (ФВ). Последние исследования показывают, что ФВ, объем и размер ЛЖ не являются чувствительными маркерами для определения дисфункции ЛЖ и прогнозирования послеоперационных исходов. Новые методы визуализации миокарда - тканевая допплер-эхокардиография (ТД) и метод отслеживания частиц speckle tracking (STE) - дали возможность исследования механики движения сердца, позволили проводить раннюю диагностику и контроль лечения сердечной недостаточности, прогнозировать возникновение НРС, определять латентную дисфункцию миокарда и прогноз при клапанных пороках. Особенно актуальным является определение функции левого предсердия (ЛП) (в основном для контроля лечения аритмий), ушка ЛП (для прогноза тромбообразования).

Известно, что фибрилляция предсердий (ФП) осложняет течение пороков сердца, вызы- вая повреждение его отделов, особенно левых. Повышение давления в ЛП, объемная перегрузка в результате аортального и митрального пороков приводят к структурным изменениям ЛП с формированием фиброза, что способствует развитию предсердных аритмий. ФП развивается в $30-40 \%$ случаев у пациентов с ревматическими митральными пороками, чаще у больных старше 65 лет с увеличением размера ЛП более 50 мм [1-3]. Развитие предсердных аритмий повышает риск неблагоприятных событий у пациентов с митральными пороками и прежде всего вызывает инсульты.

\section{Материал и методы}

В Научном центре сердечно-сосудистой хирургии им. А.Н. Бакулева за период с октября 2010 г. по апрель 2014 г. было обследовано 144 пациента с аортальными и митральными пороками: 99 мужчин и 45 женщин в возрасте

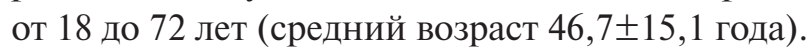
Распределение больных по возрасту и полу представлено в таблице 1.

Критерии включения в исследование: аортальная недостаточность II-IV степени, аортальный стеноз, стеноз и недостаточность (выше I степени) аортального клапана (АК), митральный стеноз, митральная недостаточность II-IV степени, стеноз и недостаточность (выше

Таблица 1

Распределение больных по возрасту и полу

\begin{tabular}{l|c|c|c|c}
\hline Группы & $\begin{array}{c}18-39, \\
n(\%)\end{array}$ & $\begin{array}{c}40-59, \\
n(\%)\end{array}$ & $\begin{array}{c}60-79, \\
n(\%)\end{array}$ & $\begin{array}{c}\text { Всего, } \\
n(\%)\end{array}$ \\
\hline Мужчины & $35(24)$ & $50(35)$ & $14(10)$ & $99(69)$ \\
Женщины & $2(1)$ & $29(20)$ & $14(10)$ & $45(31)$ \\
Всего & $37(25)$ & $79(55)$ & $28(20)$ & $144(100)$ \\
\hline
\end{tabular}




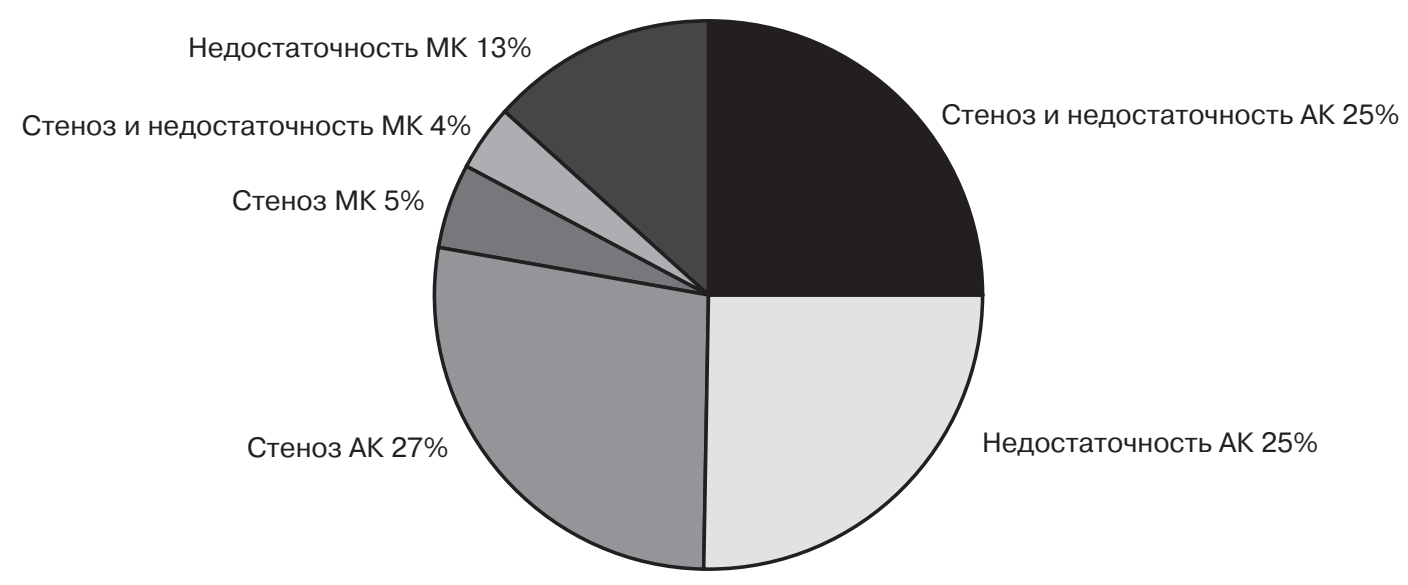

Рис. 1. Распределение больных по группам в зависимости от порока

I степени) митрального клапана (МK). Критериями исключения из исследования было наличие сопутствующей хронической почечной недостаточности, постинфарктного кардиосклероза, противопоказаний к проведению операции с искусственным кровообращением.

На рисунке 1 представлена диаграмма распределения больных по группам в зависимости от поражения AK и МК сердца: 1-я группа с недостаточностью АК - 36 больных (25\%); 2-я группа со стенозом АK - 39 больных (27\%), 3-я группа со стенозом MK - 7 пациентов (5\%); 4-я группа со стенозом и недостаточностью МК - 6 пациентов (4\%); 5-я группа с недостаточностью МK - 20 больных (13\%); 6-я группа со стенозом и недостаточностью АК - 36 пациентов (25\%).

Всем больным при поступлении проводились общеклиническое обследование по стандартной методике, рентгенография, электрокардиография (ЭКГ), эхокардиография (ЭхоКГ) - в том числе ТД, STE, векторный анализ (VVI) 2D-изображения. По показаниям проводилось холте- ровское мониторирование ЭКГ, коронаро- и ангиография, магнитно-резонансная томография (МРТ) с контрастным усилением. Общеклиническое обследование, рентгенография, ЭКГ, ЭхоКГ с ТД, STЕ и VVI выполнялись также через 8-14 дней и через 12-36 мес после хирургической коррекции порока.

На рисунке 2 представлена схема дизайна исследования.

В качестве конечных точек, отражающих неблагоприятный прогноз, выбраны НРС. В зависимости от наличия осложнений пациенты были разделены на группы, отражающие прогноз: группа 0 - пациенты без НРС в послеоперационном периоде; группа 1 - больные, у которых в послеоперационном периоде были НРС (ФП, желудочковая тахикардия (ЖТ), блокады ножек пучка Гиса).

Выраженные клинические проявления заболевания отмечены во всех группах. Из 144 пациентов у 5 больных (3\%) по данным ЭКГ и анамнеза была выявлена исходно постоянная форма

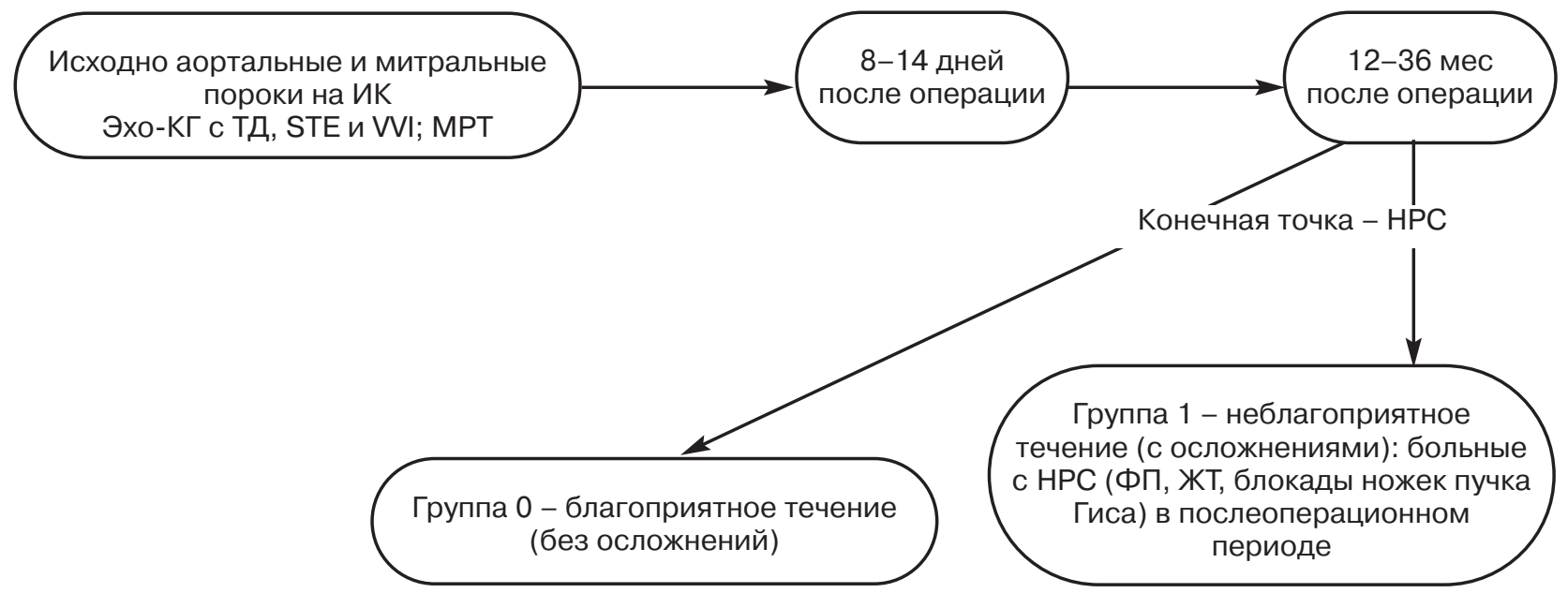

Рис. 2. Схема дизайна исследования 
Подаортальная мембрана
Инфекционный эндокардит
Миксоматоз
Дегенерация
Ревматизм
Врожденные пороки сердца

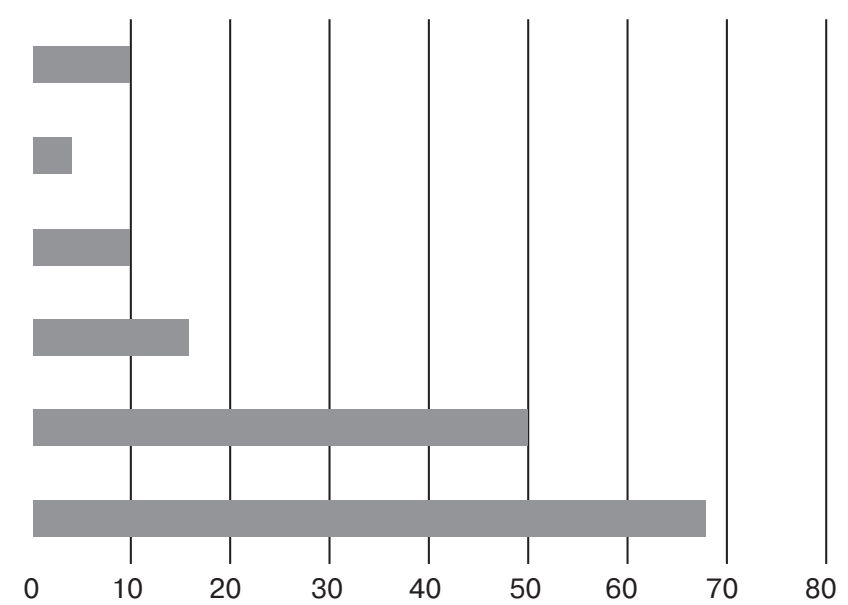

Количество больных

Рис. 3. Этиология пороков

ФП, у 14 пациентов (10\%) - персистирующая форма ФП, у 3 больных (2\%) выявлена пароксизмальная форма ФП, у 8 больных (6\%) определена пароксизмальная форма трепетания предсердий, у 9 обследованных (6\%) наблюдалась полная блокада левой ножки пучка Гиса (рис. 3).

Для проведения статистического анализа данных использовались следующие методы:

- критерий Колмогорова-Смирнова для проверки на нормальность распределений наблюдаемых признаков;

- для определения различий между группами $t$-критерий Стьюдента, критерий Ньюмана-Кейлса и критерий Даннета для нормально распределенных переменных, непараметрические статистические методы (критерий Манна-Уитни, критерий

Сравнение средних показателей двух групп*

\begin{tabular}{|c|c|c|c|}
\hline Показатель & Группа без НРС & Группа с НРС & $p$ \\
\hline $\begin{array}{l}\text { Конечный } \\
\text { диастолический объем, мл }\end{array}$ & $148,5 \pm 53$ & $181,9 \pm 69$ & 0,013 \\
\hline $\begin{array}{l}\text { Средний объем ЛП } \\
\text { (перед зубцом } P \text { на ЭКГ), мл }\end{array}$ & $73,4 \pm 29$ & $106,4 \pm 35$ & 0,014 \\
\hline Фракция укорочения, \% & $38 \pm 7,9$ & $34,4 \pm 7,8$ & 0,046 \\
\hline $\begin{array}{l}\text { Время изоволюмического } \\
\text { расслабления ЛЖ (норма } 65 \pm 20), \text { мс }\end{array}$ & $75,4 \pm 26$ & $99,6 \pm 39$ & 0,013 \\
\hline $\begin{array}{l}\text { Миокардиальный стресс по меридиану } \\
\text { (по МРТ), г/см² }\end{array}$ & $75,8 \pm 15,8$ & $96,1 \pm 16$ & 0,040 \\
\hline $\begin{array}{l}\text { Миокардиальный систолический } \\
\text { стресс по меридиану (по ЭхоКГ), г/см² }\end{array}$ & $52,7 \pm 21,8$ & $65,0 \pm 24,2$ & 0,0196 \\
\hline Е/A ЛЖ & $1,1 \pm 0,4$ & $1,8 \pm 1,0$ & 0,0014 \\
\hline $\begin{array}{l}\text { Интеграл линейной } \\
\text { скорости потока ВОЛЖ, см }\end{array}$ & $20,4 \pm 5,5$ & $16,4 \pm 5,4$ & 0,019 \\
\hline E/A ПЖ & $33,5 \pm 33,8$ & $18,8 \pm 25,3$ & 0,046 \\
\hline Индекс сферичности & $0,6 \pm 0,1$ & $0,7 \pm 0,1$ & 0,0039 \\
\hline $\begin{array}{l}\text { Интегральный систолический } \\
\text { индекс ремоделирования }\end{array}$ & $103,1 \pm 24,1$ & $85,7 \pm 20,7$ & 0,0014 \\
\hline $\begin{array}{l}\text { Продольное смещение } \\
\text { латеральной части ФК ТК, мм }\end{array}$ & $16,8 \pm 6,3$ & $11,6 \pm 4,8$ & 0,015 \\
\hline $\begin{array}{l}\text { Средняя скорость } \\
\text { ротации верхушки ЛЖ (по VVI), \%с }\end{array}$ & $45,2 \pm 21$ & $9,8 \pm 3,8$ & 0,019 \\
\hline
\end{tabular}

\footnotetext{
* Выбраны показатели, значимо отличающиеся друг от друга.
} 
Показатели со значимой предсказательной ценностью для НРС в послеоперационном периоде

\begin{tabular}{|c|c|c|}
\hline Параметр & $\begin{array}{c}\text { Значение } \\
\text { порога отсечения }\end{array}$ & $\begin{array}{l}\text { AUC - площадь } \\
\text { под кривой }\end{array}$ \\
\hline Конечный диастолический размер & $6,37 \mathrm{~cm}$ & $0,657 \pm 0,065$ \\
\hline Конечный систолический размер & $4,45 \mathrm{~cm}$ & $0,657 \pm 0,066$ \\
\hline Конечный диастолический объем & 199 мл & $0,64 \pm 0,065$ \\
\hline ИКДО & 91,27 мл/м² & $0,66 \pm 0,067$ \\
\hline ИКСО & $28,18 \mathrm{мл} / \mathrm{M}^{2}$ & $0,709 \pm 0,061$ \\
\hline Индекс относительной толщины стенки (по МРТ) & 0,41 & $0,96 \pm 0,099$ \\
\hline Перегородочно-латеральный размер ЛП & $4,4 \mathrm{~cm}$ & $0,63 \pm 0,062$ \\
\hline $\begin{array}{l}\text { Средний объем ЛП во время ранней диастолы } \\
\text { перед сокращением (перед зубцом } P \text { на ЭКГ) }\end{array}$ & 123,5 мл & $0,66 \pm 0,82$ \\
\hline Индексированный средний объем ЛП & 44,38 мл/м² & $0,63 \pm 0,065$ \\
\hline Амплитуда движения септальной части ФК МК & $0,84 \mathrm{~cm}$ & $0,62 \pm 0,066$ \\
\hline Пиковый градиент на аортальном клапане & 42 мм рт. ст. & $0,6 \pm 0,066$ \\
\hline Средний градиент на аортальном клапане & 11,5 мм рт. ст. & $0,66 \pm 0,063$ \\
\hline Время изоволюмического расслабления & 88,9 мс & $0,68 \pm 0,063$ \\
\hline $\begin{array}{l}\text { Отношение ранней диастолической скорости } \\
\text { митрального потока к поздней }(E / A \text { ЛЖ) }\end{array}$ & 1,52 & $0,74 \pm 0,093$ \\
\hline Интеграл линейной скорости потока ВОЛЖ & $17,8 \mathrm{~cm}$ & $0,69 \pm 0,083$ \\
\hline $\begin{array}{l}\text { Расстояние от } Q R S \text { до пика сокращения } \\
\text { боковой стенки ЛЖ }(Q R S-P L)\end{array}$ & $355 \mathrm{Mc}$ & $0,66 \pm 0,088$ \\
\hline Миокардиальный систолический стресс по меридиану (по ЭхоКГ) & 49,57 г/см² & $0,64 \pm 0,062$ \\
\hline Миокардиальный стресс по меридиану (по МРТ) & $78,11 г / \mathrm{cm}^{2}$ & $0,84 \pm 0,107$ \\
\hline Интегральный систолический индекс ремоделирования & 87,7 & $0,72 \pm 0,06$ \\
\hline Индекс миокардиального стресса в диастолу & 0,76 & $0,66 \pm 0,061$ \\
\hline Время замедления раннего диастолического потока* & $203,5 \mathrm{Mc}$ & $0,662 \pm 0,098$ \\
\hline Деформация пресистолической релаксации & $1,19 \%$ & $0,85 \pm 0,061$ \\
\hline Средняя продольная деформация ЛП & $26,85 \%$ & $0,69 \pm 0,075$ \\
\hline Средняя продольная деформация ПП & $21,5 \%$ & $0,73 \pm 0,089$ \\
\hline Средняя скорость ротации верхушки ЛЖ (по VVI) & $22,95 \%$ & $0,83 \pm 0,128$ \\
\hline
\end{tabular}

* Этот показатель влиял на прогноз и в раннем, и в позднем послеоперационном периодах.

Круаскала-Уоллиса) применялись в тех случаях, когда закон распределения исследуемых величин отличался от нормального;

- для определения различий между исследованиями, проходившими в динамике, - парный $t$-критерий Стьюдента, дисперсионный анализ повторных измерений для нормально распределенных показателей, непараметрические методы - критерий Вилкоксона, критерий Фридмана;

- проверка гипотезы о равенстве распределения дихотомических показателей в группах осуществлялась с помощью критерия $\chi^{2}$;

- корреляционный анализ Пирсона или Спирмена;

- методы регрессионного анализа (бинарная логистическая регрессия);
- ROC-анализ с построением ROC-кривых, графиков, позволяющих оценить качество бинарной классификации.

\section{Результаты}

\section{Предикторы нарушений ритма сердца}

В таблице 2 представлено сравнение средних показателей группы больных без нарушений ритма и с нарушениями ритма в послеоперационном периоде.

Для выявления предикторов неблагоприятного прогноза использовался ROC-анализ.

Анализ эхокардиографических данных с построением ROC-кривых и определением площади под кривой (AUC) выявил значимую прогностическую ценность у следующих показателей 
Модели, отражающие риск наступления НРС в послеоперационном периоде

\begin{tabular}{l|c|c|c}
\hline \multicolumn{1}{c|}{ Параметр } & Коэффициент $\beta$ & $\begin{array}{c}\text { Стандартная } \\
\text { ошибка }\end{array}$ & $p^{*}$ \\
\hline Относительная толщина стенки в диастолу (по МРТ) & $-17,8882$ & 5,658624 & $\mathbf{0 , 0 0 1 6}$ \\
Фракция укорочения & $-0,0608$ & 0,026141 & $\mathbf{0 , 0 2 0 1}$ \\
$E / A$ ЛЖ & 0,6909 & 0,266896 & $\mathbf{0 , 0 0 9 6}$ \\
Продольное смещение латеральной части ФК ТК (по ТД) & $-0,1501$ & 0,053087 & 0,2403 \\
Торсион ЛЖ & $-0,3447$ & 0,293573 & $\mathbf{0 , 0 0 4 7}$ \\
Относительная толщина стенки в диастолу (по МРТ) & $-18,3146$ & 5,626242 & $\mathbf{0 , 0 0 1 1}$ \\
Фракция укорочения & $-0,0515$ & 0,024325 & $\mathbf{0 , 0 3 4 3}$ \\
E/А ЛЖ & 0,7277 & 0,260101 & $\mathbf{0 , 0 0 5 1}$ \\
Диаметр ФК МК в диастолу & 0,0553 & 0,069122 & 0,4235 \\
Продольное смещение латеральной части ФК ТК (по ТД) & $-0,156$ & 0,053535 & $\mathbf{0 , 0 0 3 6}$ \\
Относительная толщина стенки в диастолу (по МРТ) & $-18,0357$ & 5,631032 & $\mathbf{0 , 0 0 1 4}$ \\
Фракция укорочения & $-0,0519$ & 0,024292 & $\mathbf{0 , 0 3 2 8}$ \\
$E / A$ ЛЖ & 0,7355 & 0,257601 & $\mathbf{0 , 0 0 4 3}$ \\
Продольное смещение латеральной части ФК ТК (по ТД) & $-0,1523$ & 0,053473 & $\mathbf{0 , 0 0 4 4}$ \\
\hline
\end{tabular}

* Выделены статистически значимые показатели $p$.

(табл. 3): конечный диастолический размер (КДР), конечный систолический размер (КСР) (рис. 4), индекс конечного диастолического объема (ИКДО), индекс конечного систолического объема (ИКСО) (рис. 5), перегородочно-латеральный размер ЛП, средний объем ЛП во время ранней диастолы перед сокращением (перед зубцом $P$ на ЭКГ) (рис. 6), индексированный средний объем ЛП, толщина межжелудочковой перегородки (МЖП) в диастолу, амплитуда движения септальной части фиброзного кольца (ФК) МК, фракция укорочения, пиковый градиент на АК (рис. 7), средний градиент на АК (рис. 8), время изоволюмического расслабления, отношение ранней диастолической скорости митрального потока к поздней $(E / A)$ ЛЖ (рис. 9), интеграл линейной скорости потока выходного отдела левого желудочка (ВОЛЖ) (рис. 10), расстояние от $Q R S$ до пика сокращения боковой стенки ЛЖ $(Q R S-P L)$, миокардиальный систолический стресс по данным ЭхоКГ, миокардиальный стресс по меридиану по данным МРТ (рис. 11), интегральный систолический индекс ремоделирования, индекс миокардиального стресса в диастолу (рис. 12), время замедления раннего диастолического потока (этот показатель влиял на прогноз и в раннем, и в позднем послеоперационном периодах (рис. 10), скорость ротации верхушки ЛЖ по данным VVI (рис. 13), деформация пресистолической релаксации ЛЖ, средняя продольная деформация ЛП, средняя продольная деформация правого предсердия (ПП) (рис. 14). Таким образом, прогностической значимостью для НРС (ФП, трепетание предсердий) в послеоперационном периоде обладают увеличенные объемы и размеры ЛЖ, ЛП, увеличенный индекс относительной толщины стенки по данным МРТ, миокардиальный стресс ЛЖ, сниженный интегральный систолический индекс ремоделирования, функция митрального кольца, деформация ЛП и ПП, сниженные скорости ротации верхушки ЛЖ.

В результате многофакторного анализа, построения регрессионной модели Кокса выявлена максимально качественная модель прогноза НРС, состоящая из индекса относительной толщины стенки на уровне папиллярных мышц по данным МРТ сердца с контрастным усилением, фракции укорочения, отношения $E / A$ ЛЖ, продольного смещения латеральной части ФК трикуспидального клапана (ТК) по данным ТД. Максимальный коэффициент $\beta$, а значит, максимальное влияние на прогноз, было выявлено для индекса относительной толщины стенки на уровне папиллярных мышц по данным МРТ сердца с контрастированием, отношения $E / A$ ЛЖ, скручивания ЛЖ.

В таблице 4 представлены модели, состоящие из показателей, которые в совокупности разделяют пациентов с НРС и пациентов 

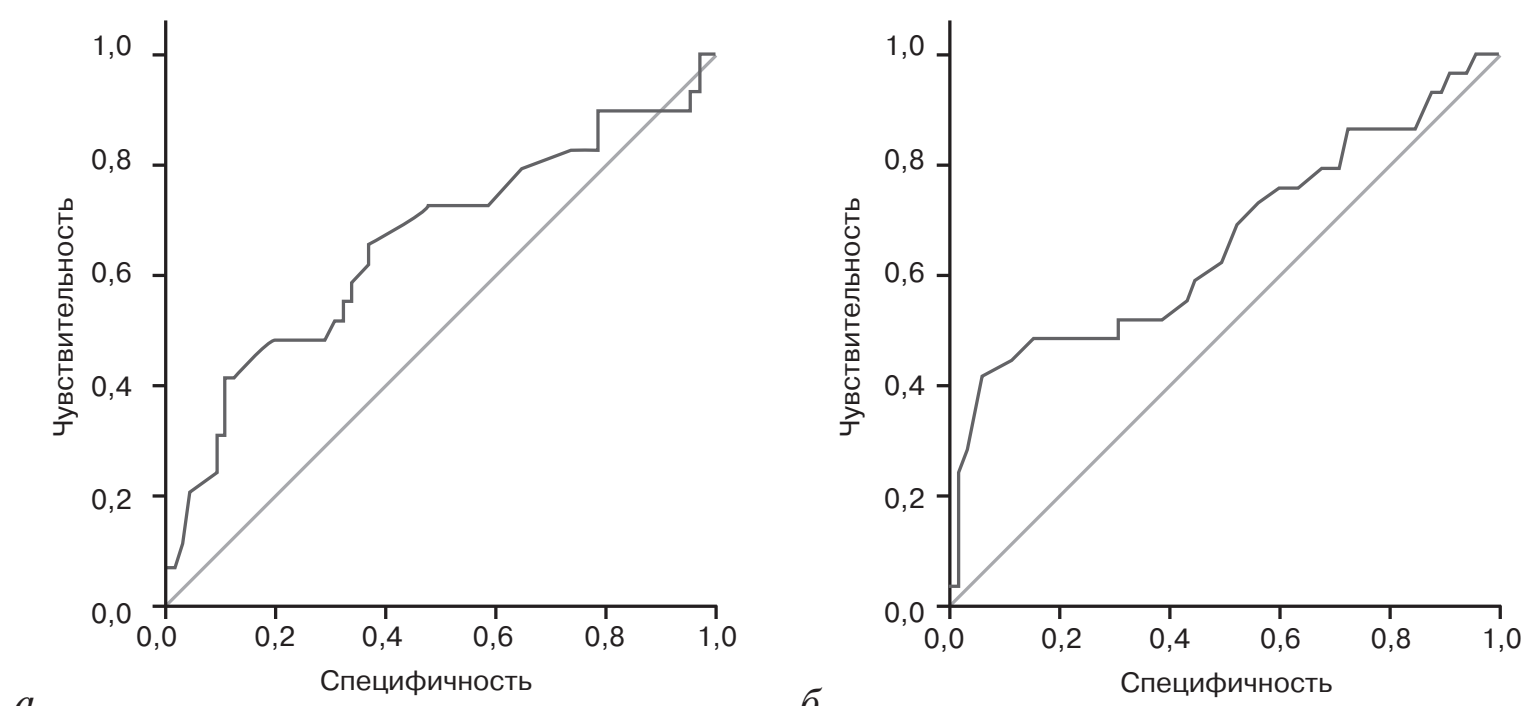

Рис. 4. ROC-кривые:

$a$ - конечного диастолического размера (AUC $0,657 \pm 0,065) ; \sigma$ - конечного систолического размера (AUC $0,657 \pm 0,066$ )

Рис. 5. ROC-кривые индексированного конечного диастолического объема (AUC 0,66士0,067) и индексированного конечного систолического объема

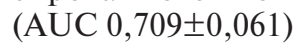
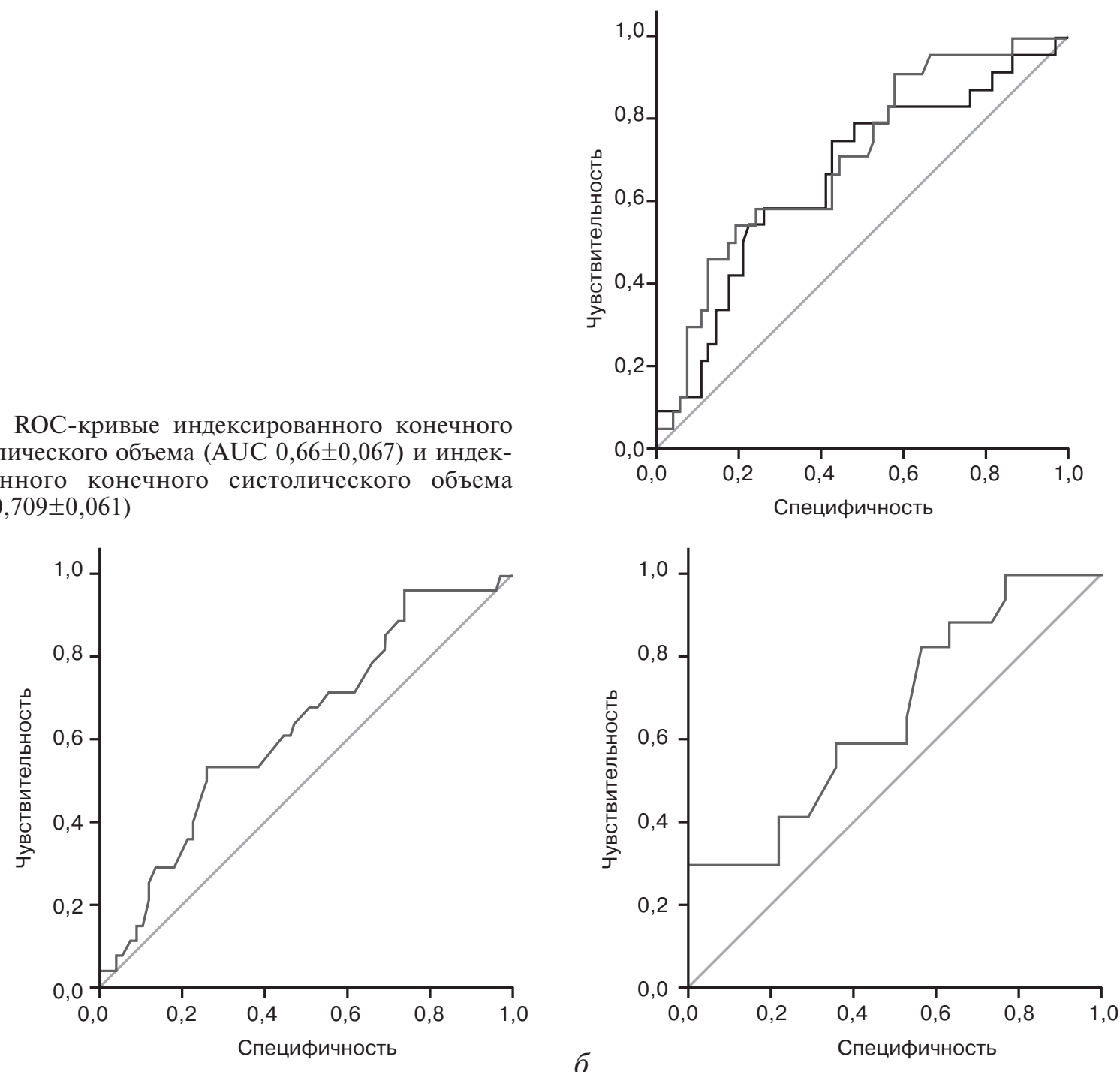

Рис. 6. ROC-кривые:

$a$ - перегородочно-латерального размера левого предсердия (AUC $0,636 \pm 0,062$ ); $\sigma$ - среднего объема левого предсердия перед со-

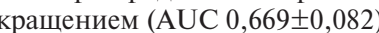



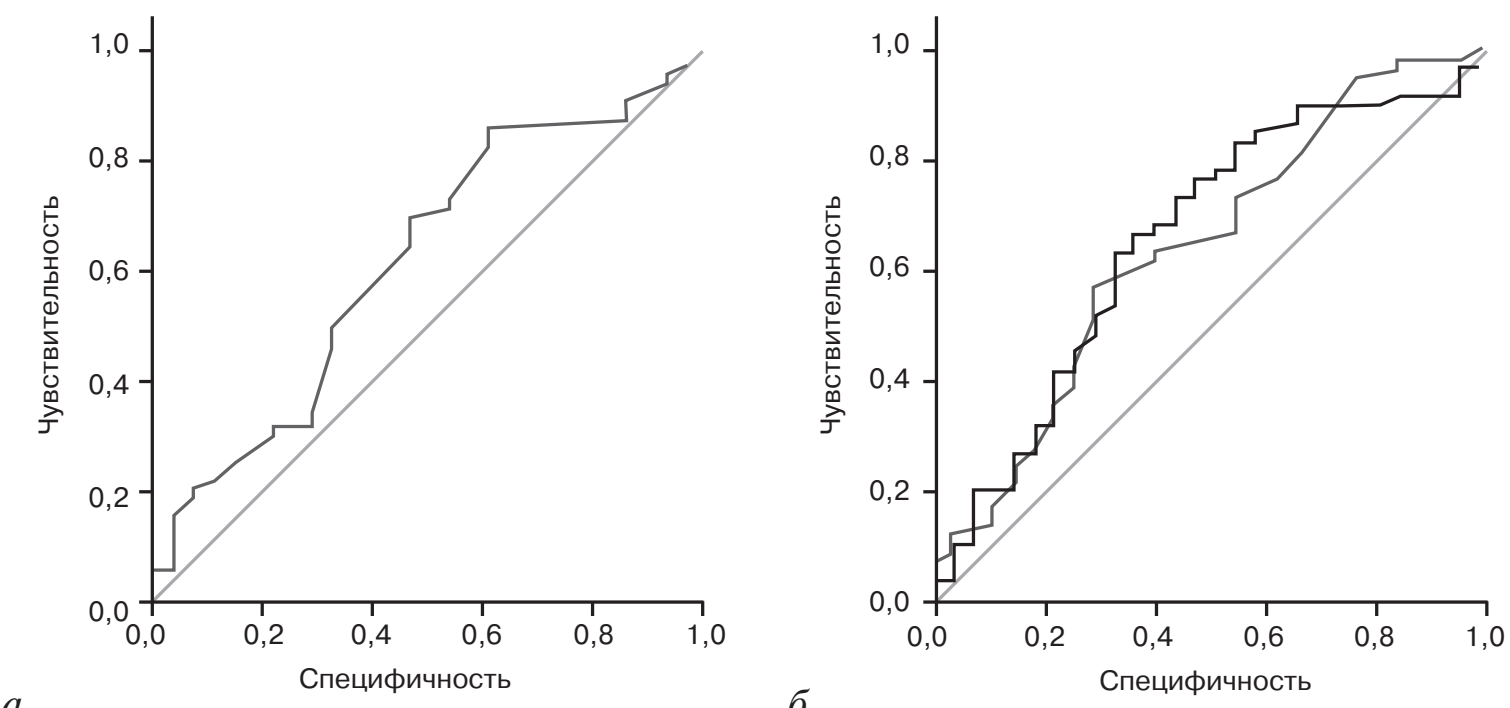

Рис. 7. ROC-кривые:

$a$ - амплитуды движения септальной части фиброзного кольца митрального клапана (AUC $0,62 \pm 0,066$ ); $\sigma$ - фракции укорочения (AUC $0,63 \pm 0,066$ ) и пикового градиента на аортальном клапане (AUC $0,65 \pm 0,066$ )

Рис. 8. ROC-кривая среднего градиента на аортальном клапане (AUC 0,659 $\pm 0,063$ )

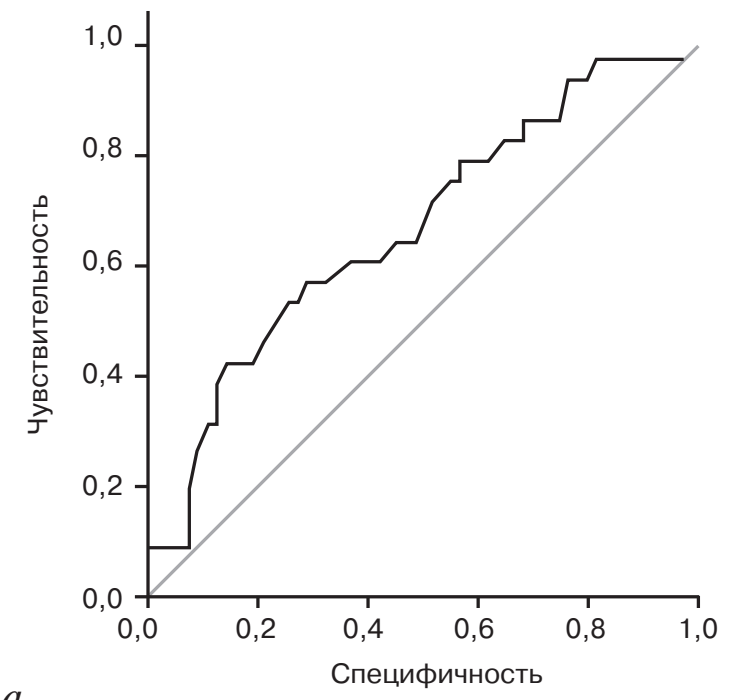

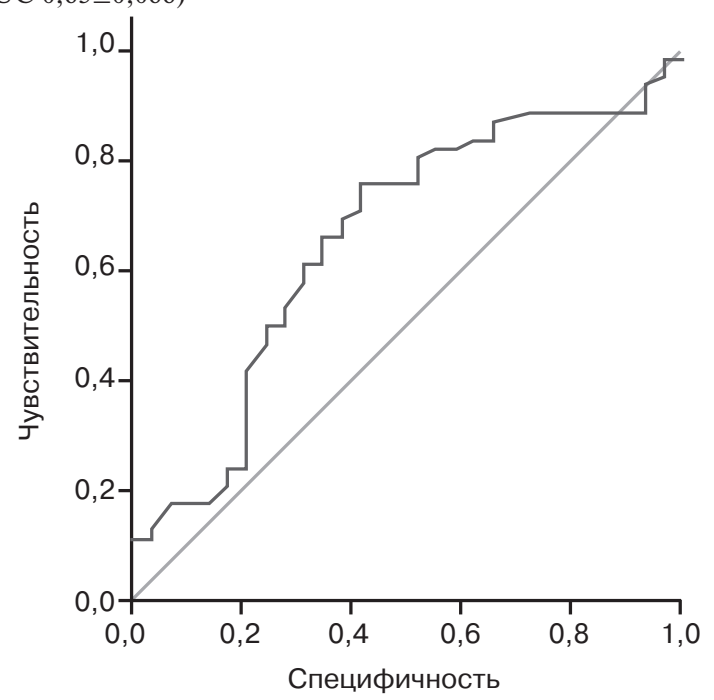

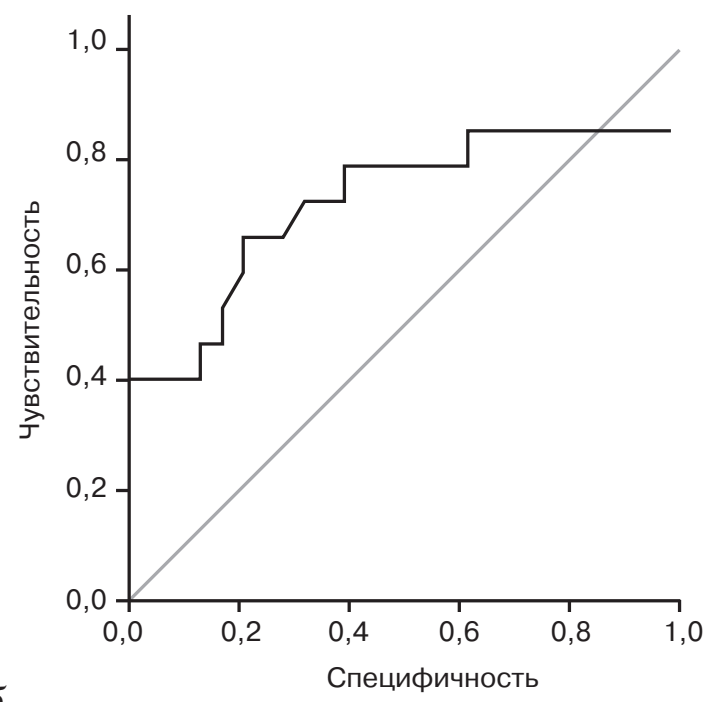

$\sigma$

$a$ - времени изоволюмической релаксации левого желудочка (AUC $0,69 \pm 0,063$ ); $\sigma$ - отношения $E / A$ левого желудочка (AUC $0,738 \pm 0,093)$ 

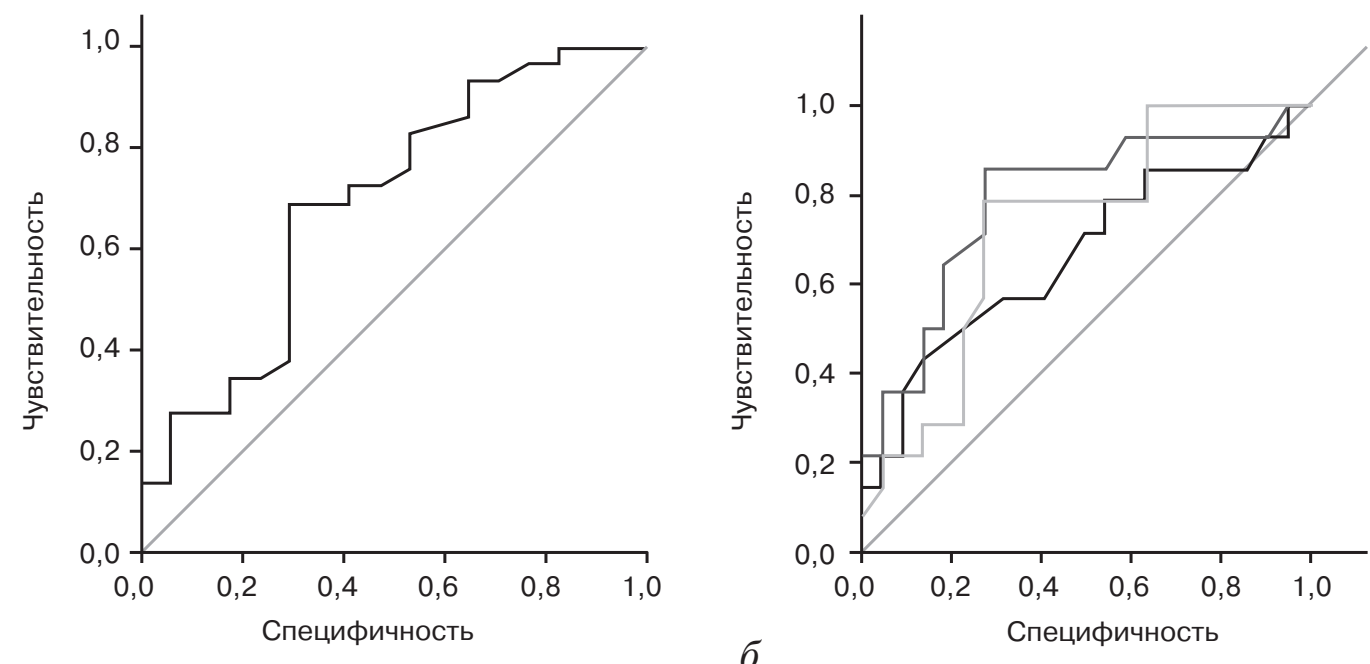

Рис. 10. ROC-кривые:

$a$ - интеграла линейной скорости потока ВОЛЖ (AUC $0,69 \pm 0,083) ; \sigma$ - времени замедления потока $E$ исходно (AUC 0,66 $\pm 0,098)$, через 10 дней после операции (AUC $0,786 \pm 0,082$ ) и через 12 мес после операции (AUC 0,72 $\pm 0,086$ )

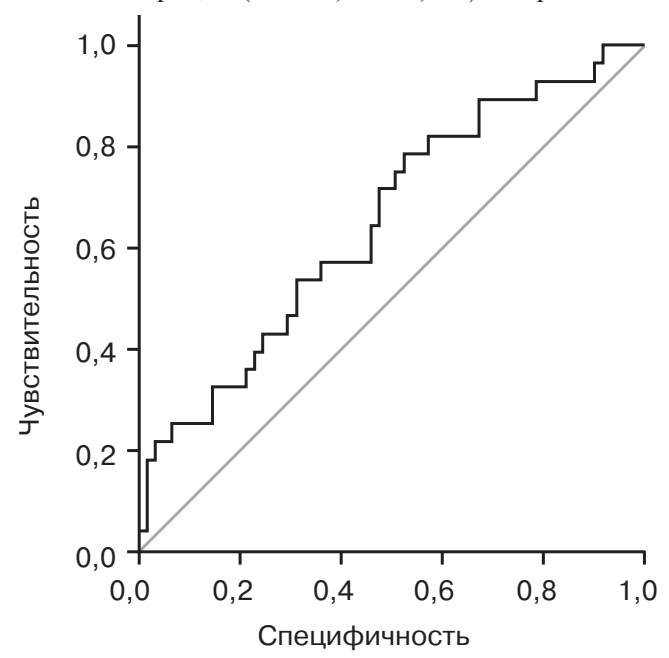

$a$

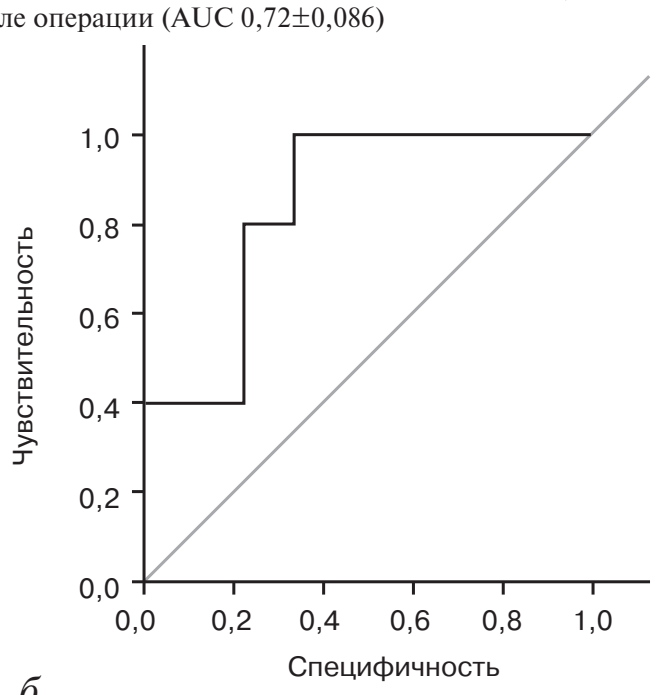

Рис. 11. ROC-кривые:

$a$ - систолического миокардиального стресса левого желудочка по меридиану по данным ЭхоКГ (AUC $0,65 \pm 0,062$ ); 6 - систолического миокардиального стресса левого желудочка по меридиану по данным MPT (AUC $0,84 \pm 0,107)$
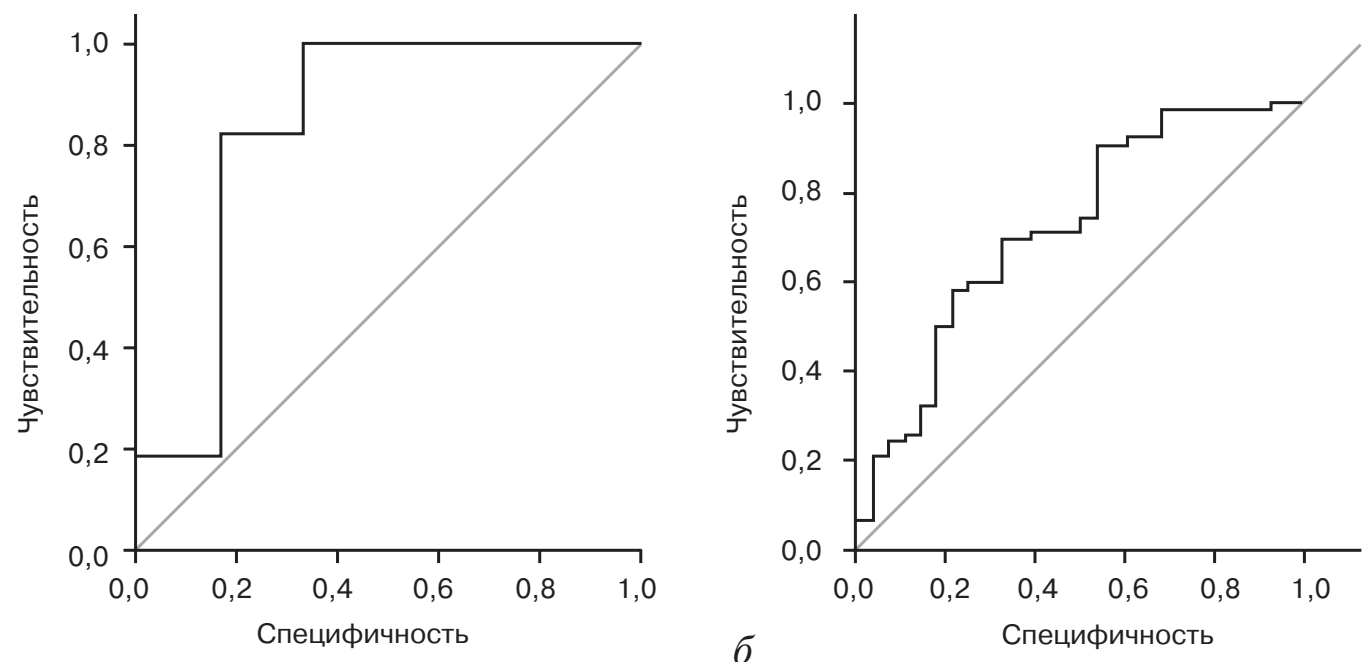

Рис. 12. ROC-кривые:

$a$ - интегрального систолического индекса ремоделирования (AUC $0,72 \pm 0,06$ ); $\sigma$ - индекса миокардиального стресса (AUC $0,665 \pm 0,061$ ) 

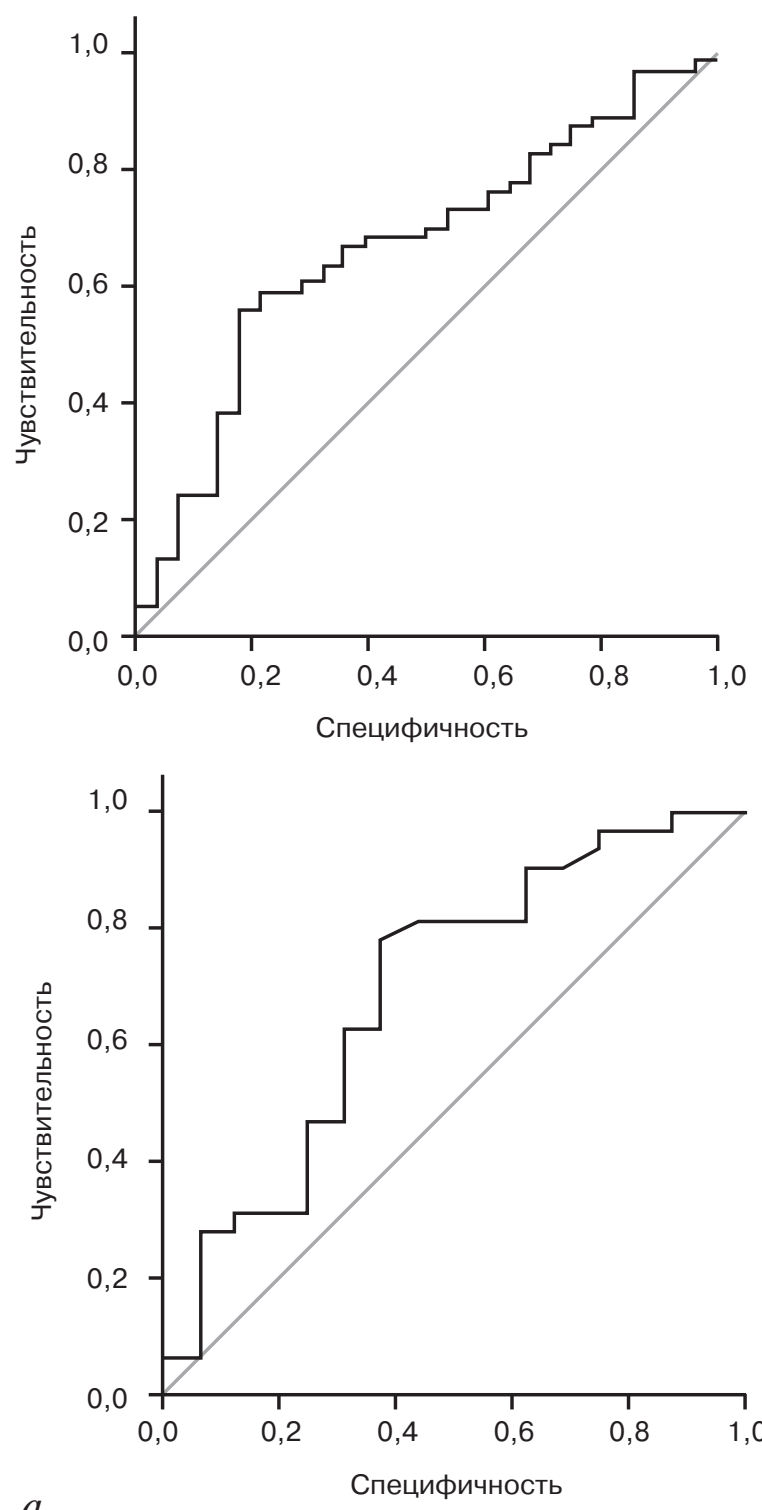

Рис. 13. ROC-кривая средней скорости ротации верхушки левого желудочка по данным VVI (AUC $0,833 \pm 0,128)$

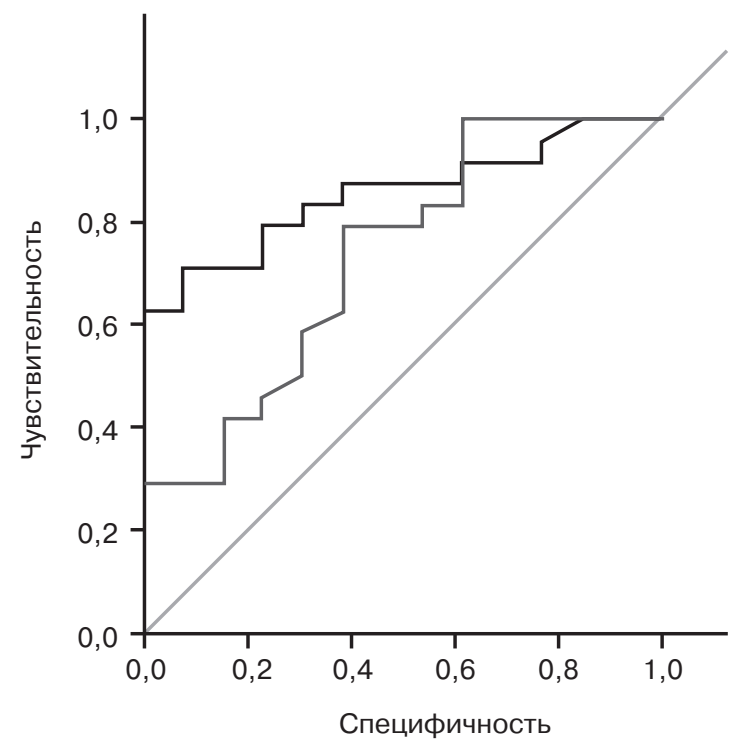

Рис. 14. ROC-кривые:

$a$ - средней продольной деформации левого предсердия (AUC $0,691 \pm 0,085)$ по данным VVI; $\sigma$ - деформации пресистолической релаксации левого желудочка (AUC $0,85 \pm 0,061)$ и средней продольной деформации правого предсердия (AUC $0,73 \pm 0,089)$ по данным VVI

без осложнений. В последней модели, выделенной серым цветом, все показатели достоверно определяют риск наступления осложнений, поэтому она максимально отражает прогноз.

\section{Обсуждение}

В настоящее время факторами риска развития нарушений ритма сердца, являются: систолическая и диастолическая сердечная недостаточность, повышенное конечное диастолическое давление в ЛЖ, длительное искусственное кровообращение (ИК), возраст, тип оперативного вмешательства, наличие артериальной гипертензии, длительность существования ФП (длительность более года увеличивает вероятность ФП после операции).

Риск ФП увеличивается в 4,5-5,9 раза на фоне хронической сердечной недостаточности $(\mathrm{XCH})$ [1]. Она возникает в 5-10\% случаев при начальных проявлениях ХСН, в 10-26\% случаев - при умеренно выраженной ХCH, в $50 \%$ случаев - на фоне выраженной ХСН [2]. Наличие ФП ухудшает прогноз сердечной недостаточности, она может являться триггером декомпенсации сердечной недостаточности. Исследования показали, что ФП чаще развивается у пациентов с артериальной гипертензией на фоне диастолической дисфункции, переходящей в систолическую [1-4]. 
В последнее время стало известно, что добавление процедуры Кокса-Мейза к протезированию или пластике клапанов сердца при наличии ФП позволяет сохранить синусовый ритм после операции. Так, 82\% пациентов после пластики митрального клапана с процедурой Кокса-Мейза сохраняли синусовый ритм в течение 2 лет, а также имели низкую частоту инсультов; если же эта процедура не выполнялась, синусовый ритм после пластики МК сохраняли только $52 \%$ больных. Процедура Кокса-Мейза не увеличивала периоперационную летальность и, таким образом, способствовала более благоприятному течению послеоперационного периода в плане свободы от нарушений ритма [5-8].

По данным литературы, с увеличением камер сердца возрастает риск возникновения ФП [9].

Данные НЦССХ им. А.Н. Бакулева указывают на то, что продолжительность ИК и время пережатия аорты при коррекции врожденных пороков сердца, наличие до операции хронической сердечной недостаточности IIA и IІБ стадий, проведение хирургической коррекции дефекта МЖП при уровне общего охлаждения ниже $32{ }^{\circ} \mathrm{C}$ являются предикторами развития послеоперационных нарушений ритма [10]. Факторами риска развития ФП в ранние сроки после коронарного шунтирования, по данным Центра, являются: возраст старше 65 лет, длительность $P$-волны более 100 мс, дисперсия $P$-волны более $40 \mathrm{мc}$, гипокалиемия (менее $2,8 \mathrm{MM} / л)$ и искусственная вентиляция легких более 24 ч после операции [11].

Целью данного исследования стало изучение возможностей эхокардиографических методов визуализации и МРТ сердца с контрастированием для прогнозирования НРС у больных с приобретенными пороками сердца в послеоперационном периоде.

В результате исследования выявлено, что прогностической значимостью для развития НРС (ФП, трепетания предсердий) в послеоперационном периоде обладают увеличенные объемы (ИКСО: точка разделения 28,18 мл/м², AUC $0,709 \pm 0,061 ; \quad$ ИКДО: точка разделения

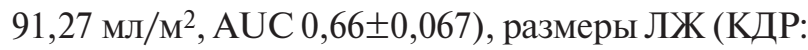
точка разделения 6,37 cM, AUC 0,657 $\pm 0,065$; KCP: точка разделения $4,45 \mathrm{~cm}, \mathrm{AUC} 0,657 \pm 0,066)$ и ЛП (точка разделения 4,4 см, AUC 0,63 $\pm 0,062$ ), увеличенный индекс относительной толщины стенки по данным МРТ сердца с контрастированием (точка разделения 0,41 , AUC $0,96 \pm 0,099$ ), миокардиальный стресс ЛЖ (точка разделения

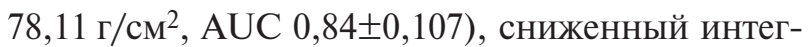
ральный систолический индекс ремоделирования (точка разделения 87,7, AUC 0,72 $\pm 0,06$ ), функция митрального кольца (точка разделения $0,84 \mathrm{~cm}$, AUC $0,62 \pm 0,066$ ), деформация ЛП (точка разделения $26,85 \%$, AUC $0,69 \pm 0,075$ ) и ПП (точка разделения $21,5 \%$, AUC $0,73 \pm 0,089)$, сниженные скорости ротации верхушки ЛЖ (точка разделения $22,95 \%$, AUC $0,83 \pm 0,128$ ).

Полученные показатели прогноза отражают не только наличие систолической и диастолической дисфункции миокарда, ремоделирование сердца, приводящее к сердечной недостаточности, но и изменение функции митрального кольца, снижение деформации ЛП и ПП, а также изменение механики движения сердца (снижение скорости ротации верхушки ЛЖ).

Эхокардиографическим предиктором сохранения ФП в послеоперационном периоде, по данным литературы, является увеличение размера ЛП более 50 мм в результате возрастания давления в ЛП. С прогрессированием повреждения миокарда при пороках сердца уменьшаются эластические свойства миокарда и увеличивается диастолическое давление, что заставляет МК открываться раньше [9]. Отношение $E / A$ становится больше 2, скорость волны $A$ уменьшается. Это рестриктивная диастолическая дисфункция. Другой важной причиной увеличения давления в ЛП является уменьшение времени изоволюмической релаксации и времени замедления волны $E$ [12]. По полученным данным, уменьшенное время изоволюмического расслабления (точка разделения 88,9 мс, AUC $0,68 \pm 0,063$ ) и увеличенное отношение $E / A$ (точка разделения 1,52 , AUC $0,74 \pm 0,093$ ) были предикторами ФП после операции.

В данной работе было показано, что время замедления раннего диастолического потока влияло на прогноз и в раннем, и в позднем послеоперационном периодах (точка разделения 203,5 мс, AUC 0,662 $\pm 0,098)$. На прогноз также влияли миокардиальный стресс - и по данным ЭхоКГ, и по данным МРТ сердца с контрастированием, - интегральный систолический индекс ремоделирования, продольная деформация ЛП и ПП, средняя скорость ротации верхушки ЛЖ.

В результате многофакторного анализа, построения регрессионной модели Кокса выявлена максимально качественная модель прогноза НРС, состоящая из индекса относительной толщины стенки на уровне папиллярных мышц по данным МРТ, фракции укорочения, отношения $E / A$ ЛЖ, продольного смещения латеральной ча- 
сти ФК ТК по данным ТД. Максимальный коэффициент $\beta$, а значит, максимальное влияние на прогноз, было выявлено для индекса относительной толщины стенки на уровне папиллярных мышц по данным МРТ сердца с контрастированием, отношения $E / A$ ЛЖ, скручивания верхушки ЛЖ.

\section{Заключение}

Прогностической значимостью для НРС (ФП, трепетание предсердий) у больных с приобретенными пороками сердца в послеоперационном периоде обладают увеличенные объемы и размеры ЛЖ и ЛП, повышенный индекс относительной толщины стенки по данным МРТ сердца с контрастированием, миокардиальный стресс ЛЖ, сниженный интегральный систолический индекс ремоделирования, нарушенная функция митрального кольца, сниженная деформация ЛП и ПП и скорости ротации верхушки ЛЖ. Показатели, обладающие прогностической ценностью для НРС в послеоперационном периоде у больных с пороками сердца, отражают универсальный процесс ремоделирования с развитием диастолической, систолической дисфункции, повреждение продольной, циркулярной функции ЛЖ, продольной функции ЛП, ПП и повреждение функции МК. Новые методы исследования (ТД и STE) позволяют оценивать сниженную деформацию предсердий, изменения механики движения ЛЖ, которые, в свою очередь, приводят к повышению вероятности возникновения НРС в послеоперационном периоде.

\section{Библиографический список}

1. Camm A.J., Kirchof P., Lip G.Y.H., Schotten U., Savelieva I., Ernst S. et al. Guidelines for the management of atrial fibrillation. Europace. 2010; 12: 1360-420.

2. Krum H., Gilbert R.E. Demographics and concomitant disorders in heart failure. Lancet. 2003; 362: 147-58.

3. Grigioni F., Avierinos J.F., Ling L.H., Scott C.G., Bailey K.R., Tajik A.J., Frye R.L., Enriquez-Sarano M. Atrial fibrillation complicating the course of degenerative mitral regurgitation: determinants and long-term outcome. JACC. 2002; 40: 84-92.

4. Машина Т.В., Голухова Е.3. Диастолическая дисфункция левого желудочка у больных с фибрилляцией предсердий: патогенетические механизмы и современные ультразвуковые методы оценки (аналитический обзор). Креативная кардиология. 2014; 4: 43-52.

5. Abreu Filho C.A.C., Lisboa L.A., Dallan L.A. Effectiveness of the Maze procedure using cooled-tip radiofrequency ablation in patients with permanent atrial fibrillation and rheumatic mitral valve disease. Circulation. 2005; 112: I20-5.

6. Gallinov A.M. Ablation of atrial fibrillation with mitral valve surgery. Cur. Opin. Cardiol. 2015; 20: 107-14.

7. Saint L.L., Damiano R.G., Cuculich P.S. Incremental risk of the Cox-Maze IV procedure for patients with atrial fibrillation undergoing mitral valve surgery. J. Thorac. Cardiovasc. Surg. 2013; 146: 1072-7.
8. Je H.G., Shuman D.G., Ad N. A systematic review of minimally invasive surgical treatment for atrial fibrillation: a comparison of the Cox-Maze procedure, beating-heart epicardial ablation, and the hybrid procedure on safety and efficacy. Eur. $J$. Cardiothorac. Surg. 2015; 48 (4): 1-11.

9. Freudenberger R.S., Wilson A.C., Kostis J.B. AFFIRM Investigators and Committees. Comparison of rate versus rhythm control for atrial fibrillation in patients with left ventricular dysfunction (from the AFFIRM Study). Am. J. Cardiol. 2007; 100: 247-52.

10. Бокерия Л.А., Зеленикин М.А., Голухова Е.З., Батов С.М. Нарушения ритма сердца и проводимости в раннем послеоперационном периоде после хирургической коррекции врожденных пороков сердца у детей раннего возраста. $A H-$ налы аритмологии. 2012; 9 (1): 24-32.

11. Бокерия Л.А., Мерзляков В.Ю., Голухова Е.З., Фарафонова Т.Н., Какучая Т.Т. Нарушения ритма сердца в ранние сроки после операции коронарного шунтирования на работающем сердце. Креативная кардиология. 2007; 1-2: 154-66.

12. Pederson O.D., Brendorp B., Elming H., Pehrson H., Kober L., Torp-Pedersen C. Does conversion and prevention of atrial fibrillation enhance survival in patients with left ventricular dysfunction? Evidence from the Danish Investigations of Arrhythmia and Mortality ON Dofetilide/(DIAMOND) study. Card. Electrophysiol. Rev. 2003; 7: 220-4.

\section{References}

1. Camm A.J., Kirchof P., Lip G.Y.H., Schotten U., Savelieva I., Ernst S. et al. Guidelines for the management of atrial fibrillation. Europace. 2010; 12: 1360-420.

2. Krum H., Gilbert R.E. Demographics and concomitant disorders in heart failure. Lancet. 2003; 362: 147-58.

3. Grigioni F., Avierinos J.F., Ling L.H., Scott C.G., Bailey K.R., Tajik A.J., Frye R.L., Enriquez-Sarano M. Atrial fibrillation complicating the course of degenerative mitral regurgitation: determinants and long-term outcome. JACC. 2002; 40: 84-92.

4. Mashina T.V., Golukhova E.Z. Left ventricular diastolic dysfunction in patients with atrial fibrillation: pathogenetic mechanisms and modern ultrasound estimation techniques (an analytical review). Kreativnaya kardiologiya. 2014; 4: 43-52 (in Russian).

5. Abreu Filho C.A.C., Lisboa L.A., Dallan L.A. Effectiveness of the Maze procedure using cooled-tip radiofrequency ablation in patients with permanent atrial fibrillation and rheumatic mitral valve disease. Circulation. 2005; 112: I20-5.

6. Gallinov A.M. Ablation of atrial fibrillation with mitral valve surgery. Cur. Opin. Cardiol. 2015; 20: 107-14.

7. Saint L.L., Damiano R.G., Cuculich P.S. Incremental risk of the Cox-Maze IV procedure for patients with atrial fibrillation undergoing mitral valve surgery. J. Thorac. Cardiovasc. Surg. 2013; 146: 1072-7.

8. Je H.G., Shuman D.G., Ad N. A systematic review of minimally invasive surgical treatment for atrial fibrillation: a comparison of the Cox-Maze procedure, beating-heart epicardial ablation, and the hybrid procedure on safety and efficacy. Eur. $J$. Cardiothorac. Surg. 2015; 48 (4): 1-11.

9. Freudenberger R.S., Wilson A.C., Kostis J.B. AFFIRM Investigators and Committees. Comparison of rate versus rhythm control for atrial fibrillation in patients with left ventricular dysfunction (from the AFFIRM Study). Am. J. Cardiol. 2007; 100: 247-52.

10. Bockeria L.A., Zelenikin M.A., Golukhova E.Z., Batov S.M. Heart rhythm and conduction disturbances in early postoperative period after surgical correction for congenital heart defects in infants. Annaly aritmologii. 2012; 9 (1): 24-32 (in Russian).

11. Bockeria L.A., Merzlyakov V.Yu., Goluhova E.Z., Farafonova T.N., Kakuchaya T.T. The arrhythmias early after coronary artery bypass surgery on a beating heart. Kreativnaya kardiologiya. 2007; 1-2: 154-66 (in Russian).

12. Pederson O.D., Brendorp B., Elming H., Pehrson H., Kober L., Torp-Pedersen C. Does conversion and prevention of atrial fibrillation enhance survival in patients with left ventricular dysfunction? Evidence from the Danish Investigations of Arrhythmia and Mortality ON Dofetilide/(DIAMOND) study. Card. Electrophysiol. Rev. 2003; 7: 220-4.

Поступила 25.08.2015 Подписана в печать 15.09 .2015 